\title{
How concentrated is crime among victims? A systematic review from 1977 to 2014
}

\author{
SooHyun $\mathrm{O}^{1}$, Natalie N. Martinez ${ }^{1}$, YongJei Lee ${ }^{2}$ and John E. Eck ${ }^{{ }^{*}}$
}

\begin{abstract}
Background: Considerable research shows that crime is concentrated among a few victims. However, no one has systematically compared these studies to determine the level of concentration and its variation across studies. To address this void in our knowledge of repeat victimization, we conducted a systematic review and meta-analysis of the evidence that crime is concentrated among victims.

Methods: We distinguished between studies of victimization prevalence, which examine both victims and nonvictims, and studies of victimization frequency, which only examine subjects that were victimized once or more. We identified 20 prevalence studies and 20 frequency studies that provided quantitative information sufficient for analysis. We organized data using visual binning and fitted logarithmic curves to the median values of the bins.

Results: We found that crime is concentrated within a small proportion of the subjects in both the prevalence studies and frequency studies, but also that it is more concentrated in the former. When we compared studies of business victimization to studies of household victimization, we found that victimization is more concentrated among households than among businesses in prevalence studies, but that the reverse is true for frequency studies. A comparison between personal and property victimizations shows that the patterns of re-victimizations are similar. Crime is more concentrated in the United States compared to the United Kingdom in prevalence studies, but the opposite is true when frequency studies are examined. Finally, the concentration of victimization changes over time for both the US and the UK, but the nature of that change depends on whether one is examining prevalence or frequency studies.

Conclusions: Not surprisingly, our systemic review supports the notion that a large proportion of victimizations are of a relatively small portion of the population and of a small portion of all those victimized at least once. There is no question that crime is concentrated among a few victims. However, there is also variation in concentration that we also explored.
\end{abstract}

Keywords: Concentration of crime, Victim, Systematic review, Meta-analysis, Visual binning

\section{The importance of repeat victimization}

Crime victimization is a relatively rare event in the general population. Among those who experience it, most do so only once. For example, Tseloni et al. (2004) found that $92 \%$ of British households reported experiencing no victimizations over a 1-year period. Of those households that were victimized, about $80 \%$ experienced it only once.

\footnotetext{
*Correspondence: john.eck@uc.edu

1 School of Criminal Justice, University of Cincinnati, Cincinnati, OH, USA Full list of author information is available at the end of the article
}

Conversely, the few households that were repeatedly victimized in a year accounted for $40 \%$ of the crimes in that period (Tseloni et al. 2004).

The proportion of the population that is ever victimized and the proportion that is victimized repeatedly varies over studies. Several studies suggest that over $8 \%$ of the population experiences victimization and that more than half of all victims experienced crime more than twice (Lauritsen and Quinet 1995; Osborn et al. 1996; Sparks 1981). For example, Lauritsen and Quinet (1995) found that about half of the National Youth Survey participants 
experienced at least one larceny victimization. Among these victims almost $60 \%$ experienced larceny victimization more than once. However, most repeat victimizations happen to a small fraction of those ever victimized (Ellingworth et al. 1995; Farrell 1995). Ellingworth et al. (1995) found that the $10 \%$ of people who experienced the most personal crime victimizations accounted for half of all personal crime victimizations in 1984. A study of small businesses found that $1 \%$ of businesses accounted for $45 \%$ of all robberies committed, and three percent of businesses accounted for $81 \%$ of all violent attacks committed (Wood et al. 1997). These findings imply that opportunities for crime are highly concentrated among a small proportion of the most afflicted repeat victims.

Scholars introduced the concept of "repeat victimization" in the late 1970s (Sparks et al. 1977). Hindelang et al. (1978) argued that looking at "multiple and recurrent victimization" might benefit public crime prevention policy by helping identify the causes of victimization. Over a decade later, the Kirkholt Project in Great Britain, initiated a successful crime control strategy focusing on repeat victims (Forrester et al. 1988, 1990). Later, the approach was extended to domestic violence (Lloyd et al. 1994), racial attacks (Sampson and Philips 1992, 1995), burglary (Webb 1997), and vehicle crimes (Chenery et al. 1997). These efforts also produced substantial crime reductions. For example, Pease (1998) evaluated a prevention effort targeting repeat victims in Stockport, England and found that this project reduced overall crime by reducing repeat victimization by $44 \%$. In sum, there is substantial evidence that repeat victimization accounts for most crimes, and that preventing repeat victimization can reduce crime.

\section{State dependence, population heterogeneity, and repeat victimization}

Research suggests two general explanations for repeat victimization-state dependence and population heterogeneity (Lauritsen and Quinet 1995; Osborn and Tseloni 1998; Wittebrood and Nieuwbeerta 2000). These are distinct concepts in theory, but they can be intertwined in practice (Tseloni and Pease 2003). State dependence is the idea that prior victimization predicts future risk because it alters something about the victim. This implies that initial victimization "boosts" the probability of experiencing a subsequent victimization (Pease 1998). For example, if an initial victimization makes a person more fearful to confront offenders, this changed behavioral pattern increases that person's vulnerability and attractiveness (Schwartz et al. 1993). However, some scholars (e.g., Nelson 1980; Sparks 1981) suggest that state dependence does not explain all repeat victimization scenarios. For example, Sparks (1981) argued that it does not explain repeat victimization involving different crime types (e.g., experiencing a robbery, followed by a burglary, followed by a car theft).

Alternatively, it may be that prior victimization changes something about offenders, rather than victims. Strong evidence suggests that repeated crimes are disproportionately the work of prolific offenders (Ashton et al. 1998, see Martinez et al. [2017, this issue] for a review of crime concentration among offenders). For example, about half of all residential burglary offenders return to the same houses (Winkel 1991) and about half of all bank robbers strike the same banks (Gill and Matthews 1993). Offenders may also provide each other with useful information about places they have previously burgled, robbed, or otherwise victimized. Thus, repeat victimization may involve different offenders (Bennett 1995; Sparks 1981). In the case of repeat violent victimization, Felson and Clarke (1998) explain that offenders' previous experiences may help them to identify victims who are least likely to resist. This boost account of offenders holds for across other types of crimes such as armed robberies (Gill and Pease 1998).

The other general explanation of repeat victimization is population heterogeneity. This explanation is also known as a "flag account" (Pease 1998) and claims that possessing certain characteristics make some people or households are more at risk for victimization. These characteristics can include biological factors (e.g., individual size or physical vulnerability), psychological propensity (e.g., submissive or aggressive personality), lifestyle (e.g., staying out late drinking), or occupation (e.g., delivering pizzas). Most people have characteristics that make them unlikely to be victimized, but some people have characteristics that make them susceptible to many victimizations. For example, Hindelang et al. (1978) explained that differences in lifestyle patterns lead a concentration of victimization among certain people and households. That is, the risk of revictimization appears to be stable for people who do not change their lifestyles in response to a previous victimization (Nelson 1980).

\section{Two measures of victimization}

Two measures of crime concentration are commonly used in the victimization literature. The first measure is "prevalence," or the number of people with at least one victimization divided by the total number of people in a population. The second measure is "frequency," or the total number of victimizations divided by the total number of victims (Hope 1995; Osborn and Tseloni 1998; Tseloni and Pease 2015; Trickett et al. 1992, 1995). These two measures suggest different crime prevention approaches. The higher the prevalence of victimization, the greater the proportion of the population at risk for 
being victimized. If a high prevalence of victimization is driving crime rates, crime can be reduced by focusing efforts on preventing a non-victim from becoming a victim. However, if crime rates are mainly due to a high frequency of victimization, crime prevention strategies should concentrate on keeping victims from being revictimized (Hope 1995; Trickett et al. 1992, 1995).

\section{The current study}

Numerous studies have demonstrated that a large proportion of victimizations happen to a relatively small portion of the population. Furthermore, a small proportion of those affected are victimized at more than once. There seems to be no question that crime is concentrated among a few victims. However, it is important for the advancement of science that we test ideas that have gained general acceptance to make sure the community of scholars have not made a collective error. No one has systematically reviewed the repeat victimization literature and meta-analyzed the findings. Consequently, there is an a priori chance that the common understanding of repeat victimization could be wrong.

Further, looking at individual studies does not tell us how concentrated victimization is generally. Therefore, this paper synthesizes the findings from multiple studies of repeat victimization to estimate overall proportion of crime that is attributed to a few repeat victims. Equally as important is the variation in concentration within populations and among victims, which may vary among studies for several reasons. First, some studies look at the prevalence of victimization and its frequency, while others only examine frequency. As a shorthand, we refer to the first set of studies as prevalence studies and the second as frequency studies.

A second reason studies may show variation in victimization concentration has to do with the type of victim. Two broad types of victimization surveys are common in the literature: surveys of households and surveys of businesses (Weisel 2005). These two types of victimization are also related to two different types of places. Thus, variation in concentration between household and business victimization might reveal how criminal opportunities vary depending on the features of places. Other kinds of victimization this study examined are property and personal victimizations. A comparison of these two types of victimization are important because different targets of crime may have different patterns of concentration.

A third reason is that the concentration of crime may vary across countries. For instance, a cross national comparative victimization study by Tseloni et al. (2004) found that the UK has higher burglary victimization concentration than the US. The comparison was based on two different nationally representative victimization surveys:
The U.S. National Crime Victimization Survey (NCVS) and the British Crime Survey (BCS). Thus, variation in concentration may be attributable to local nature of crime (Weisel 2005) or to differences in data collection processes between different surveys (Lee 2000). In this study, each country includes various types of surveys and thus, we expect greater variation between countries.

Finally, concentration of crime may vary across decades. For example, the US experienced a sharp nationwide decline in crime during the 1990s (Farrell et al. 2014). Importantly, this decline was consistent across two different measures of crime, the FBI's Uniform Crime Reports (UCR) and the National Crime Victimization Survey (NCVS). Further, the NCVS shows an even greater reduction in crime between 1991 and 2001 than the UCR does. Possible explanations for the sharp drop in crime include the use of innovative policing strategies, an increase in the number of police, increased incarceration rates, changes in crack and other drug markets, tougher gun control laws, and a stronger economy; however, the effectiveness of each of these strategies is debatable (Farrell et al. 2014; Zimring 2006; Blumstein and Wallman 2006). Accordingly, the drop in crime may have been associate with changes in crime concentration across decades.

With many studies available, we can begin to explain the concentration of victimization phenomenon by systematically reviewing and analyzing their research findings. The next section describes the methods used, including the literature search and inclusion strategy, how data was extracted, and how concentration was measured. The third section describes the analysis of this literature and our findings. In the final section, we draw conclusions and state their implications for research and policy.

\section{Data and methods}

\section{Criteria for inclusion and exclusion}

Our goal is to determine the concentration of victimization based on previous research. We need quantitative information that can describe the distribution of crime across a sample of victims. To achieve this, we required studies to have specific information describing crime among victims, which are reflected in our three criteria for inclusion in our analysis. First, the study must be written in English. Second, the study had to include empirical data from which it drew its findings-we had to be able to retrieve relevant statistics from the text of the study, or access its original data set to calculate them. Third, the study must provide statistics on the percentage of victims (X\%) in its sample and percentage of crimes (Y\%) associated with those victims. We use the combinations of these $\mathrm{X}$ and $\mathrm{Y}$ percentages as ordered pairs to plot points 
Table 1 Characteristics of the studies and ordered pairs identified and analyzed

\begin{tabular}{|c|c|c|c|c|}
\hline \multirow[t]{2}{*}{ Characteristics } & \multicolumn{2}{|l|}{ Prevalence } & \multicolumn{2}{|l|}{ Frequency } \\
\hline & Number of studies & Number of coordinates & Number of studies & Number of coordinates \\
\hline \multicolumn{5}{|l|}{ Type of victim } \\
\hline Household & 10 & 156 & 10 & 143 \\
\hline Business & 3 & 40 & 4 & 43 \\
\hline \multicolumn{5}{|l|}{ Type of crime } \\
\hline Property & 3 & 71 & 6 & 116 \\
\hline Personal & 7 & 109 & 7 & 93 \\
\hline \multicolumn{5}{|l|}{ Two nations } \\
\hline US & 8 & 188 & 7 & 144 \\
\hline UK & 12 & 193 & 12 & 180 \\
\hline \multicolumn{5}{|l|}{ US across decades } \\
\hline $1970 s$ & 5 & 140 & 5 & 122 \\
\hline $1990 \mathrm{~s}$ & 3 & 48 & 3 & 42 \\
\hline \multicolumn{5}{|l|}{ UK across decades } \\
\hline $1970 s$ & 2 & 27 & 1 & 24 \\
\hline $1980 \mathrm{~s}$ & 3 & 48 & 3 & 35 \\
\hline $1990 \mathrm{~s}$ & 6 & 55 & 6 & 64 \\
\hline $2000 \mathrm{~s}$ & 3 & 55 & 3 & 51 \\
\hline \multicolumn{5}{|l|}{ Total } \\
\hline Studies analyzed (studies identified) & $20(66)$ & $397(548)$ & $20(25)$ & $359(371)$ \\
\hline
\end{tabular}

on a logarithmic crime concentration curve. For example, Tseloni and her coauthors (2004) provided a cumulative distribution of 1412 burglary victimizations over 12,845 households in England and Wales from the 1994 British Crime Survey. In Table 1 of their study, each of the 11 rows in the first column provides the percentage of burglaries explained by the percentage of households, thus it is possible to retrieve and record these $11 \mathrm{X}-\mathrm{Y}$ ordered pairs into our database.

Since, for any single study, there may be an insufficient number of $\mathrm{X}-\mathrm{Y}$ ordered pairs to reliably represent the distribution of crime across the victims/householdsa single $\mathrm{X}-\mathrm{Y}$ ordered pair does not reliably represent the victim-crime distribution of the study-we applied another criterion to filter out the studies with too few $\mathrm{X}-\mathrm{Y}$ ordered pairs. Specifically, in addition to the points where the percent of victims is $100 \%$ or the percent of crimes is $100 \%$, relevant studies must supply at least two $\mathrm{X}-\mathrm{Y}$ ordered pairs to represent the victim-crime distribution of the data (for example, $15 \%$ of the respondents [X] had $45 \%$ of the victimizations $[\mathrm{Y}]$ and $50 \%$ of the respondents $[\mathrm{X}]$ had $100 \%$ of the victimizations $[\mathrm{Y}]$ ).

\section{Data sources and search strategy}

We searched for empirical studies addressing the concentration of victimization in journal articles, academic institutions, and government reports. First, we used keywords to conduct an electronic search for studies. To determine our keywords, we first consulted the earliest studies on victimization. We chose the baseline keywords 'victimization' from Sparks et al. (1977) and 'repeat victimization' from Hindelang et al. (1978). In our searches, we spelled "victimization" with a $\mathrm{z}$, as used in North America, and with an s, as used in Great Britain. We examined the titles, abstracts, and methods sections of each article in our search results to determine if it fits our inclusion criteria. Once we found further studies using these keywords, we chose new keywords from the studies we found and then conducted another round of online searches. In summary, we used the following keywords in our searches: victimization, re-victimization, repeated victimization, repeat victimization, concentration of victim, multiple victimization, distribution of victimization, heterogeneity of victimization, state-dependence of victimization, and frequency of victimization. ${ }^{1}$ The databases we searched were: Criminal Justice Abstracts, EBSCO, ProQuest, Google, and Google Scholar.

\footnotetext{
${ }^{1}$ Our study is not dependent on any particular search term, but on the set of terms used. Further, even a term that unveils a single study might be very valuable, if that single study is largely unknown, it contains findings at variance to other studies, or it suggests other search terms that lead to many other studies. In short, we treated the search terms not as independent items, but as part of a large web of terms.
} 
Second, we manually examined bibliographies of retrieved studies for additional studies to include. If we found a relevant study from the bibliography of a retrieved study, we then looked at the bibliography of the new study and repeated the process. During this iterative approach, if we found new possible keywords, we repeated the computerized searching process again across the databases. ${ }^{2}$ The bibliographies of several publications were particularly useful because they specifically focused on the phenomenon of victimization concentration (i.e., Ellingworth et al. 1995; Farrell 1995; Farrell and Pease 1993; Pease 1998; Tseloni 2000, 2006).

In addition, we presented a preliminary version of this study at the 2015 Environmental Criminology and Crime Analysis international symposium in Christchurch, New Zealand and at the 71st Annual Conference of the American Society of Criminology at Washington, DC and asked attendees if they knew any gap in our literature.

These search methods resulted in a total of 70 studies with $560 \mathrm{X}-\mathrm{Y}$ ordered pairs. However, many of these studies did not satisfy our stringent third criterion requiring at least two $\mathrm{X}-\mathrm{Y}$ ordered pairs. As shown in Table 1, when including only those studies that did, we had 20 prevalence studies with 397 ordered pairs and 20 frequency studies with 359 ordered pairs. These studies and ordered pairs are the data we examine in this paper.

\section{Coding protocol}

Our comparative analysis of crime concentration among population or victims has no precedent in the literature. Conventional meta-analysis calculates a variety of statistics including t-statistics, estimated coefficient, standard errors, and confidence intervals and then weights the data points to compensate for uncertainly in the data (Higgins and Green 2011; Mulrow and Oxman 1997). However, because we used actual values of $\mathrm{X}-\mathrm{Y}$ ordered pairs to estimate the general distribution of victimizations over possible victims, rather than estimated coefficients (as is standard in meta-analysis), it is unclear if weights improve the validity of our analysis. As our test of this indicated that weights were not helpful, we did not use them. ${ }^{3}$

\footnotetext{
${ }^{2}$ Because recording the number of studies from multiple databases without duplicates is cumbersome, particularly when using an iterative process, and it does not shed additional light on the validity of the findings of our study, we did not record the number of studies found per search engine or database.

${ }^{3}$ We tested whether weighting our data would change our results. We weighted X-Y pairs of each study by the study's sample size. We used the study's sample size $(w)$ to weight $Y$ value of each coordinate point within each bin $(i)$, then calculated the weighted median $\left(\widetilde{w_{i}}\right)$ to represent the weighted central tendency of each bin. We did not find any substantiate difference in the findings with weighted ordered pairs compared to the findings with un-weighted points (see Appendix 1).
}

For our meta-analysis, we recorded the $\mathrm{X}-\mathrm{Y}$ ordered pairs for each study in two ways. ${ }^{4}$ To analyze the prevalence of victimization, we coded the $\mathrm{X}$ and $\mathrm{Y}$ pairs based on the number of the potential victims (e.g., people or households who could have been victimized). Twenty studies had sufficient information for this purpose, yielding 397 X-Y pairs. To analyze the frequency of victimization, we coded the values of $X$ based on the number of victimization for those who experienced at least one crime (i.e., people or household who did not experience crime were dropped). Twenty studies provided frequency distributions with $359 \mathrm{X}-\mathrm{Y}$ ordered pairs (19 of these studies were also used to analyze victimization prevalence). We also coded the data with regards to the type of victim, type of crime, country of origin, and years of data collected for each study. Table 1 shows the characteristics of the studies reviewed in this paper.

\section{Synthesis of the evidence}

To answer the question of how concentrated crime is among victims, we estimated the cumulative distribution of crime using visual binning tool in SPSS 21. Each bin on the horizontal axis represents a $1 \%$ interval over the range from 0 to $100 \%$ of the victims. These bins are arrayed from victims who experienced the most crimes to non-victims with zero crimes (i.e., the first bin contains the most crime afflicted $1 \%$ of the victims and the last bin contains $1 \%$ of the victims, all of which have no crimes). We then tabulated the median values of $Y$ for each bin. We used this technique for two specific reasons. First, we assumed that $\mathrm{Y}$ values within each one-percent range bin on the horizontal $(\mathrm{X})$ axis vary, so we needed a measure of the central tendency of each one percent bin. Second, we chose the median as a representative statistic for each bin to remedy possibly skewed distributions of $Y$ values in each bin. A visual representation of the process we used can be found in Fig. 1 of Lee et al. (2017, this issue).

After calculating median values of each bin, we estimated the cumulative curve by interpolating the median values. We used the logarithmic and the power law functions as possible candidates to fit our lines. These two functions are mathematically connected: power-law behavior in either nature or social systems can be often transformed into a logarithmic scale for easier understanding on the phenomenon (Newman 2005).

To determine which function would produce a better fit, we compared their R-square statistics. Though this statistic is high for both functions, the R-square for the

\footnotetext{
${ }^{4}$ The leading author retrieved and coded $\mathrm{X}-\mathrm{Y}$ ordered pairs from the studies, and then the other co-authors reviewed the database, and calculated the raw distribution of $\mathrm{X}-\mathrm{Y}$ ordered pairs to cumulative distribution of victimizations if needed.
} 


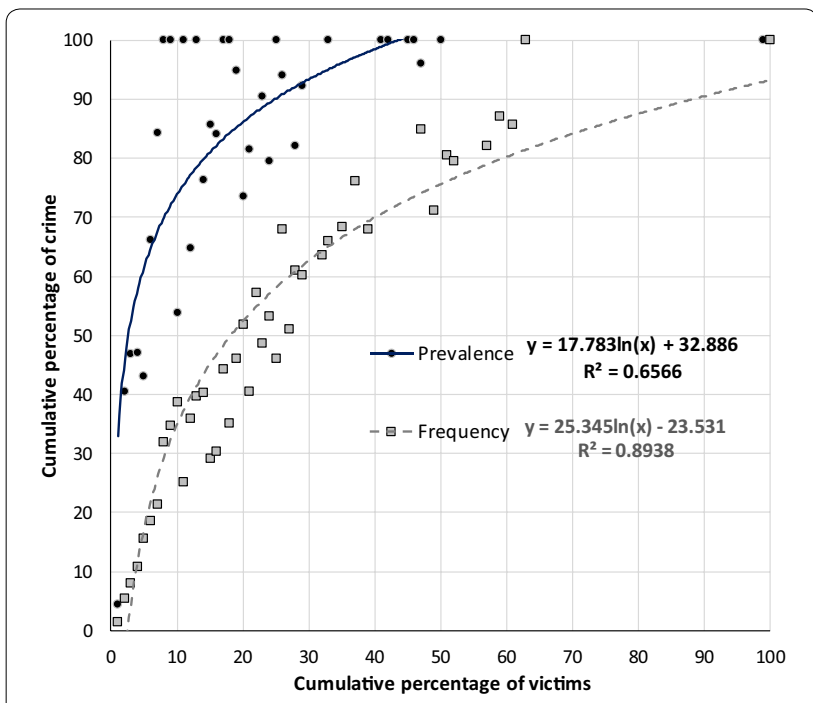

Fig. 1 Concentration of crime among victims: prevalence vs. frequency

logarithmic function is greater (see panel D in Fig. 1 of Lee et al. 2017, this issue). Therefore, we used it to estimate the distribution curve between the cumulative percentage of (binned) victims and crime. We selected only a single functional form to use throughout the analysis because we wanted to have a common standard metric for our comparisons that was simple to interpret. Further, as we anticipated comparing victim concentration to place and offender concentrations (see Eck et al. 2017, in this issue) we did not want to introduce variation in functional form.

\section{Results}

Using the 20 studies with 397 corresponding X-Y pairs for prevalence and the 20 studies with 359 corresponding $\mathrm{X}-\mathrm{Y}$ pairs for frequency, we first provide an overall comparison of the extent of crime concentration. Then, we examine how victimization concentration varies depending on victim type, crime type, between nations, and across decades in the US and the UK.

\section{Prevalence and frequency}

Figure 1 shows the concentration curves for the overall prevalence and frequency of victimization. Visually and analytically, it is obvious that crime is more concentrated when examining the population of possible targets than when only examining targets with at least one victimization. The dots on the prevalence and frequency curves (representing the bin medians) do not overlap much, and the fitted curves are clearly distinct. Estimated coefficients also provide evidence that the prevalence and frequency curves are substantially different in the victimization concentration. Using $5 \%$ of the targets as a benchmark, the difference is quite dramatic: the prevalence curve shows that $5 \%$ of the population experiences $61.5 \%$ of all victimization, whereas the frequency curve shows that top 5\% of all victims' experience $17.3 \%$ of the victimizations (see Appendix 2). When the prevalence curve hits $100 \%$ of victimizations, about half of the population has experienced some victimization. On the frequency curve, half of the victims has experienced only $75.6 \%$ of victimization.

This illustrates two sources of concentration previously identified in the literature. First, there is concentration due to the fact that most possible targets are not victimized. Population heterogeneity may be the source of this. Second, even when this is accounted for in the frequency curve, we still see concentration. Some of this may be due to state dependence.

Although both curves fit the data reasonably well (using the R-square statistics), we still can see variation around the fitted curves. This implies that the amount of concentration varies across studies. Note that this variation is understated in Fig. 1 because the dots represent median values for bins and there is variation around these median values. We turn to possible explanations for this variation next.

\section{Household victimization vs. business victimization}

One source of variation is the type of victim. Two common data sources in the literature are household and business victimization surveys (Weisel 2005). As shown in Table 1, 10 studies of households provided $156 \mathrm{X}$ and $\mathrm{Y}$ ordered pairs and three studies of businesses provided 40 $\mathrm{X}$ and $\mathrm{Y}$ pairs for the prevalence curve. For the frequency curve, the 10 studies of households provided $143 \mathrm{X}$ and $\mathrm{Y}$ pairs and the four studies of businesses provided $43 \mathrm{X}$ and $Y$ pairs. The types of crimes included in the studies of households included domestic violence (Lloyd et al. 1994; Mayhew et al. 1993), household burglary (Johnson 2008; Mayhew et al. 1993; Nelson 1980; Sidebottom 2012; Tseloni et al. 2004; and other types of victimization occurring to households (Ellingworth et al. 1995; Hindelang et al. 1978; Percy 1980; Tseloni 2006). The studies of businesses included commercial burglary (Laycock 2001), pub violence and work-based violence (Mayhew et al. 1993), business burglary and robbery (Nelson 1980) and manufacturing commercial victimization and retail commercial victimization (Pease 1998).

Figure 2 shows the distributions for prevalence and frequency for each type of victim. In the left panel of prevalence curves, we see that the two distributions are quite similar when considering the targets most involved with crime (at $5 \%$ of the targets have about $60 \%$ of the victimizations). When we consider victims above the $10 \%$ 

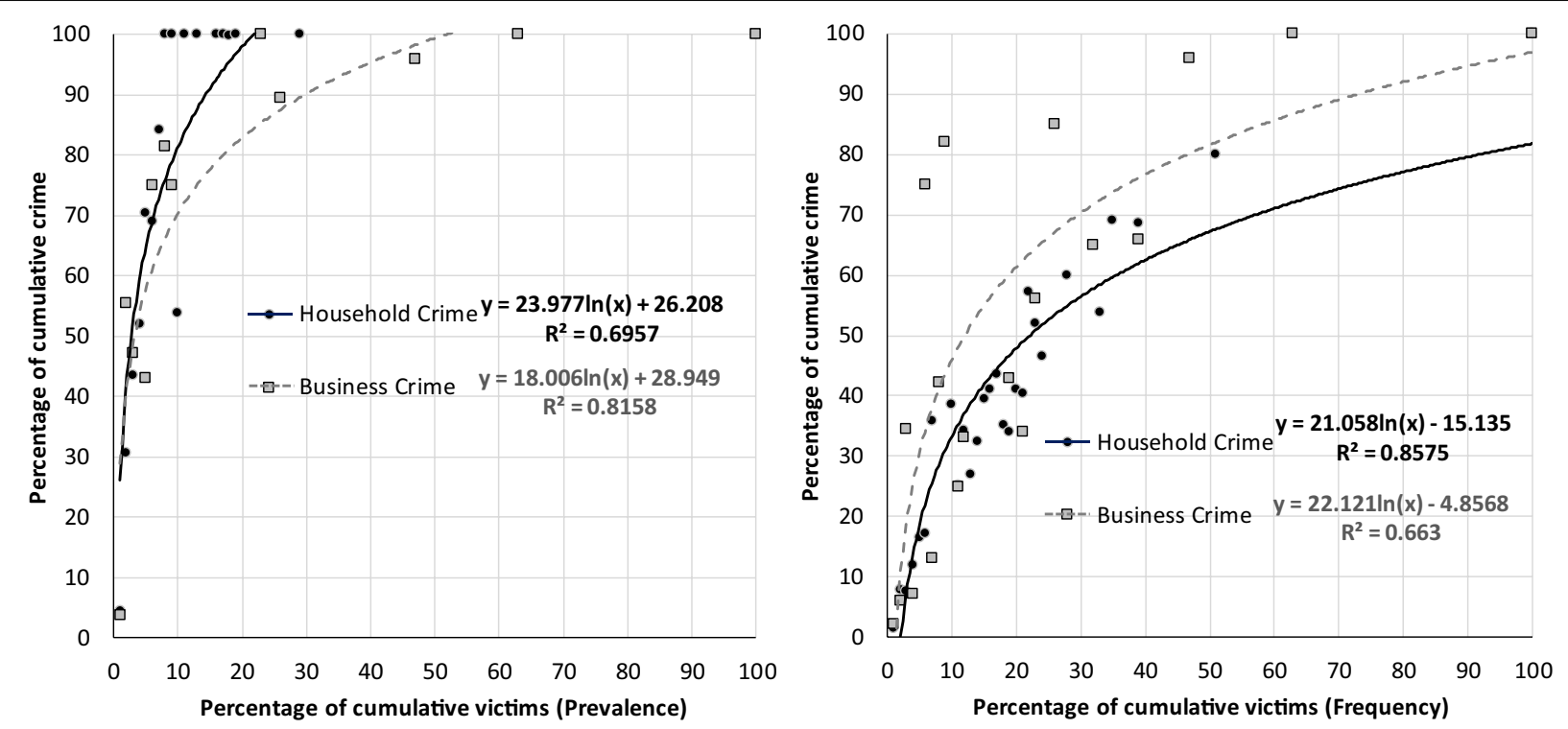

Fig. 2 Concentration of crime: household crime vs. business crime

value on the horizontal axis, the two curves diverge substantially. Importantly, about $50 \%$ of the businesses have no crime involvement whereas about $80 \%$ of households have no crime. This finding is interesting for crime prevention: it suggests that when one selects a small fraction of the most crime involved, there is no useful distinction between households and businesses. Stated differently, addressing the most crime involved $5 \%$ of households or businesses would theoretically yield equivalent results.

The frequency curves show different results. When we only consider businesses and households with at least one victimization, business victimization is more concentrated than household victimization. The most victimized $5 \%$ of businesses accounts for about $30.7 \%$ of the business victimization, whereas the most victimized $5 \%$ of the households only account for about $18.5 \%$ of the household victimizations (see Appendix 2). This suggests that repeat victimization interventions might be more useful for businesses than households. However, there is more variation around the business victimization frequency curve than the corresponding curve for households so we have less confidence in the conclusions draw from the business studies.

\section{Property victimization vs. personal victimization}

We also compared property victimization and personal victimization. For the prevalence curve, three studies of property victimization provided $71 \mathrm{X}-\mathrm{Y}$ ordered pairs (Tseloni et al. 2004; Tseloni 2006; Ellingworth et al. 1995) and seven studies of personal victimization provided 109 $\mathrm{X}-\mathrm{Y}$ ordered pairs (Ellingworth et al. 1995; Hindelang et al. 1978; Nelson 1980, 1984; Tseloni 2000; Tseloni and
Pease 2005, 2015). For the frequency curve, six studies of property victimization provided $116 \mathrm{X}-\mathrm{Y}$ ordered pairs (Ellingworth et al. 1995; Johnson 2008; Mayhew et al. 1993; Nelson 1980; Tseloni et al. 2004; Tseloni 2006) and seven studies of personal victimization provided $93 \mathrm{X}-\mathrm{Y}$ pairs (Ellingworth et al. 1995; Nelson 1980, 1984; Tseloni 2000; Tseloni and Pease 2005; Tseloni and Pease 2015).

Figure 3 shows the prevalence and frequency distributions. In the prevalence curve panel, we see that the two distributions are quite different up to $10 \%$ of the victims (on the horizontal axis), and that personal victimizations are more concentrated than property victimizations. Because both curves hit the $100 \%$ value on the vertical axis when their horizontal values are about $25 \%$, approximately $75 \%$ of targets for both types of victims experience no crime. This finding requires caution in its interpretation because the $\mathrm{R}$ square for personal victimization curve is only 0.36 and the estimated beta is not significant (beta $=12.206$, $\mathrm{t}$-statistic $=2.12$ ).

The frequency curves provide a somewhat different story. When we consider up to $20 \%$ of targets in both property and personal victimization, we do not find any substantial difference in the patterns of victim concentration. The most victimized $20 \%$ of properties and persons account for 46.7 and $51.5 \%$ of victimizations, respectively. This small difference in victimization suggests that the patterns of property and personal re-victimizations are similar once a target has been victimized once. Though we see more variation around the personal victimization curve than the property victimization curve, relatively large R-squares suggest that both frequency curves fit well through the median values of each bin. 


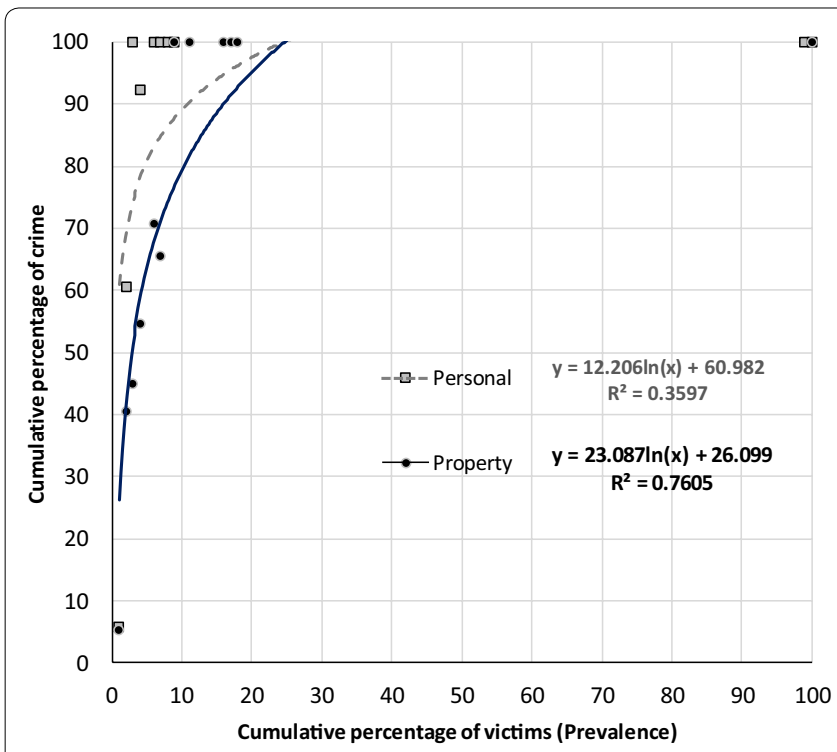

Fig. 3 Concentration of crime: personal crime vs. property crime

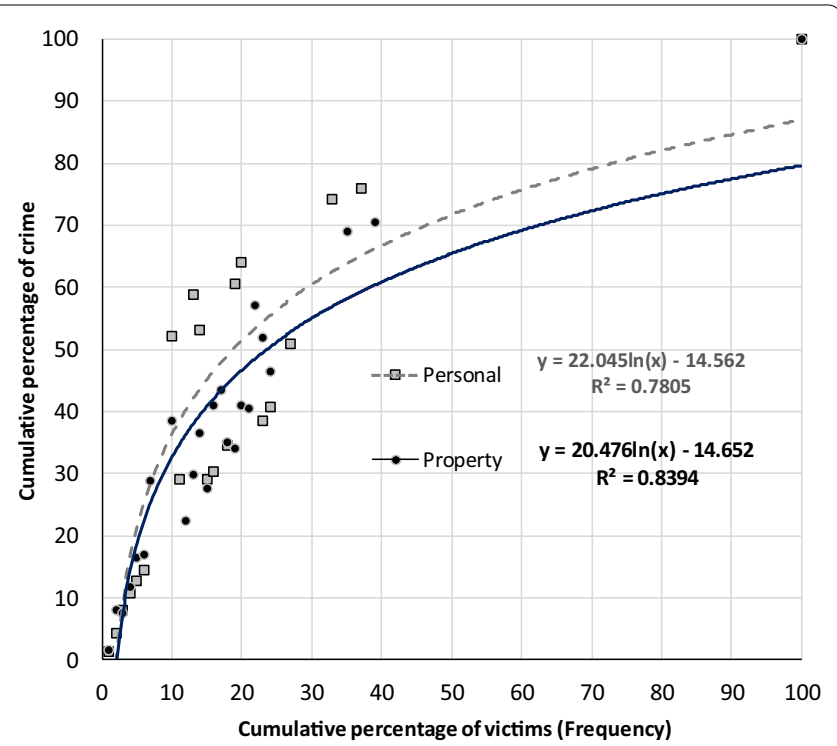

\section{US vs. UK}

Another source of variation in victimization concentration relates to the data's country of origin. The US and the UK each have their own nationally representative victimization surveys (the National Crime Victimization Survey and the British Crime Survey, respectively). In addition to studies based on these surveys, we identified other studies using other surveys either from US or from UK and we include them in this analysis.

As shown in Table 1, the eight studies using the data from the US provided $188 \mathrm{X}$ and $\mathrm{Y}$ ordered pairs for prevalence curve, and seven studies provided $144 \mathrm{X}$ and $\mathrm{Y}$ ordered pairs for frequency curve. Twelve studies using the data from the UK provides $193 \mathrm{X}$ and $\mathrm{Y}$ pairs for prevalence curve and $180 \mathrm{X}$ and $\mathrm{Y}$ pairs for frequency curve. The eight US studies use data from the National Crime Survey (Hindelang et al. 1978; Nelson 1980; Nelson 1984), the NCVS (Tseloni 2000; Tseloni and Pease 2003; Tseloni et al. 2004), National Youth Survey (Lauritsen and Quinet 1995), the National Crime Survey of Business Victimizations (Nelson 1980) and other sources, including a general citizen survey (Percy 1980) in the US The twelve UK studies use the BCS (Ellingworth et al. 1995; Farrell 1995; Farrell and Pease 1993, Mayhew et al. 1993; Tseloni et al. 2004; Tseloni 2006; Tseloni and Pease 2015), local surveys (Farrell 1995; Sparks et al. 1977), a business crime survey (Laycock 2001), a commercial victimization survey (Pease 1998), calls to the police data (Lloyd et al. 1994) or policerecorded crime data (Johnson 2008) in the U. K.

Figure 4 shows the prevalence and frequency distributions for each country. Looking at the prevalence curves, we see that the two distributions are quite different. Victimization seems to be more concentratedin the US than the UK. The most victimized $5 \%$ of the targets in the US account for $65.8 \%$ of all victimizations, whereas the most victimized $5 \%$ of the targets in the UK account for $55.4 \%$ of victimizations (see Appendix 2). At the other extreme, about $76 \%$ of the US respondents experience no crime whereas only half of the UK respondents experience no crime. These differences in number of non-victims account for differences in victimization concentration in these prevalence curves.

The frequency curves appear to show that victimization is more concentrated in the UK than in the US when we only consider people with at least one victimization. However, the difference is not large as in prevalence curve comparison. The most victimized $5 \%$ of victims accounts for $21.7 \%$ of the victimization in the UK, whereas the most victimized $5 \%$ of the victims accounts for $15.1 \%$ of the victimizations in the US (see Appendix 2). Overall, the comparisons in the prevalence and frequency curves show that there is variation in the concentration between the two nations. However, given the variation in the data for each country, we should be cautious about drawing a firm conclusion.

\section{Across decades}

Because previous studies contended that there is variation in victimization across decades (e.g., Blumstein and Wallman 2006; Zimring 2006), we look at the variation in concentration in the US and the UK over decades.

\section{US across decades}

First, we looked at the victimization concentration among the population of possible targets and the targets 

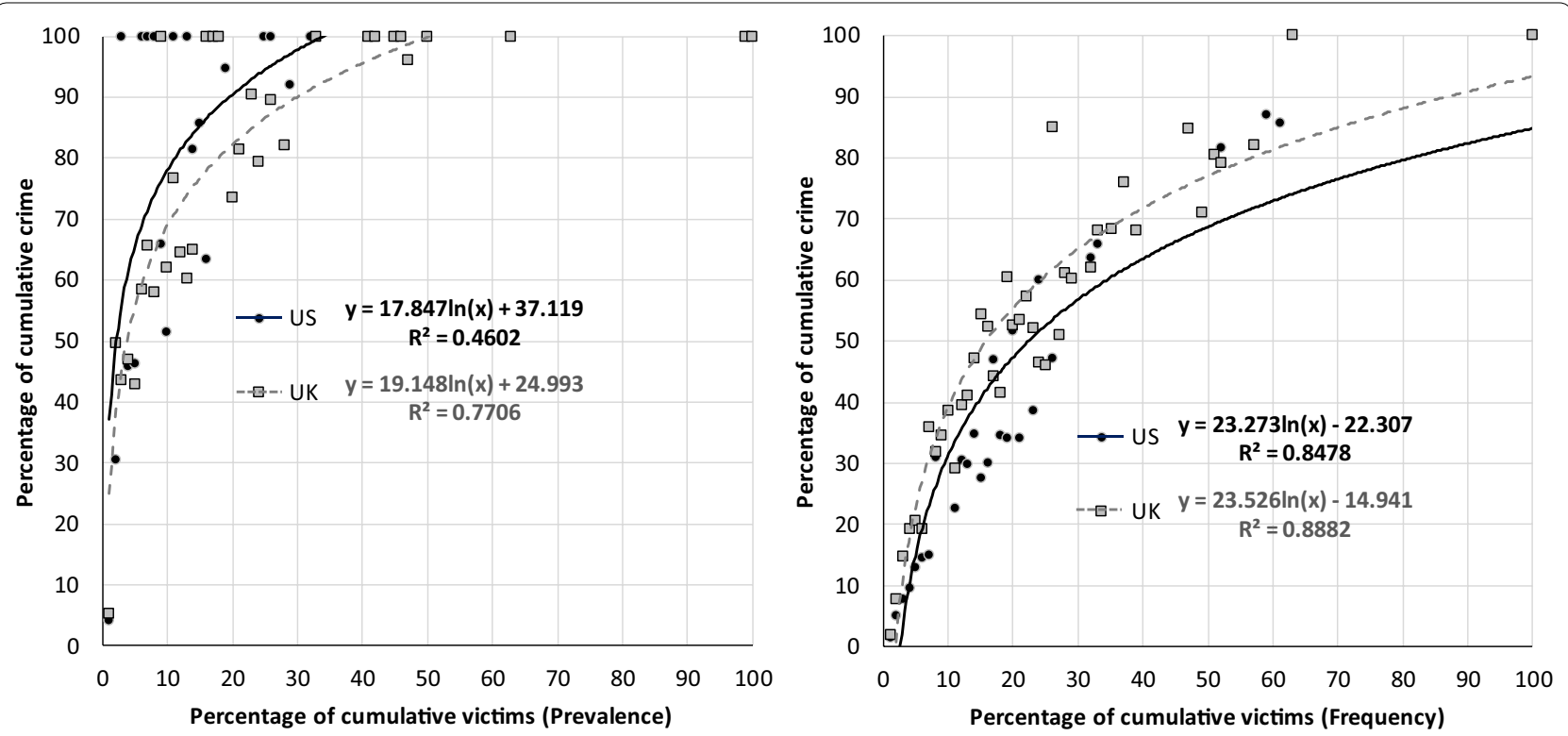

Fig. 4 Concentration of crime: US vs. UK

with at least one victimization in the US. We looked at the victimization concentration for only two decades (the 1970s and 1990s) due to the lack of studies in other decades. As shown in Table 1, we found eight studies using the data from the US with $188 \mathrm{X}-\mathrm{Y}$ ordered pairs (Hindelang et al. 1978; Lauritsen and Quinet 1995; Nelson 1980, 1984; Percy 1980; Tseloni 2000; Tseloni et al. 2004; Tseloni and Pease 2003). Five studies used the data collected from 1970s (Hindelang et al. 1978; Lauritsen and Quinet 1995; Nelson 1980, 1984; Percy 1980) and three studies used data from 1990s (Tseloni 2000; Tseloni et al. 2004; Tseloni and Pease 2003).

Figure 5 shows the distributions for prevalence and frequency for each. In the prevalence curves, we see that the two distributions are quite different. In fact, the most victimized $5 \%$ of possible targets account for $60.2 \%$ of the victimizations during 1970 whereas the top 5\% account for $81.7 \%$ of the victimizations in the 1990s (see Appendix 2). About $75 \%$ of the population experienced no victimization during 1990 s whereas $70 \%$ of the population experienced no victimizations during 1970s. This finding is consistent with victimization trend across decades with the sharp decline in all categories of crime and all parts of the nation during 1990s (Rennison 2001).

The difference between the two curves is less when we examine frequency of victimization (right panel) than between prevalence curves (left panel). This is logical because we are only looking the subset of the population who had at least one victimization. Victimization appears slightly more concentrated in the 1970s than in the 1990s. However, the right end of these curves is less reliable and of less consequence than the left end. When we look at the top $5 \%$ of the victims we see that these victims experienced $17 \%$ of the crime in the 1990 s and $15.6 \%$ of the crime in the 1970s: not a large or meaningful difference (see Appendix 2). These two frequency curves diverge more rapidly beyond the $5 \%$ value on the horizontal. The interpretation of these frequency curves is that once victimized, the likelihood of re-victimization did not change substantially in 1990s compared to 1970s.

\section{UK across decades}

We also looked at changes in the victimization concentrations among the population of possible targets and the targets with at least one victimization in the UK. In contrast to the US studies, we were able to examine each decade from the 1970s to the 2000s. We found twelve studies for the frequency curve. Among those, Sparks et al's (1977) study used data from the 1973 local survey in England for all offenses and three other studies used data from the 1982, 1984 and 1988 British Crime Surveys (Ellingworth et al. 1995; Farrell 1995; Farrell and Pease 1993). Six studies used data collected from 1990s (Ellingworth et al. 1995; Laycock 2001; Lloyd et al. 1994; Mayhew et al. 1993; Pease 1998; Tseloni et al. 2004) and three studies used data collected from 2000s (Tseloni 2006; Johnson 2008; Tseloni and Pease 2015). When a study used the data collected for several years across different decades (e.g., 1999-2003), the study was assigned to the decade for median year. In addition, some include data from more than two decades (Ellingworth et al. 1995) and two nations (Tseloni et al. 2004). In these cases, we 

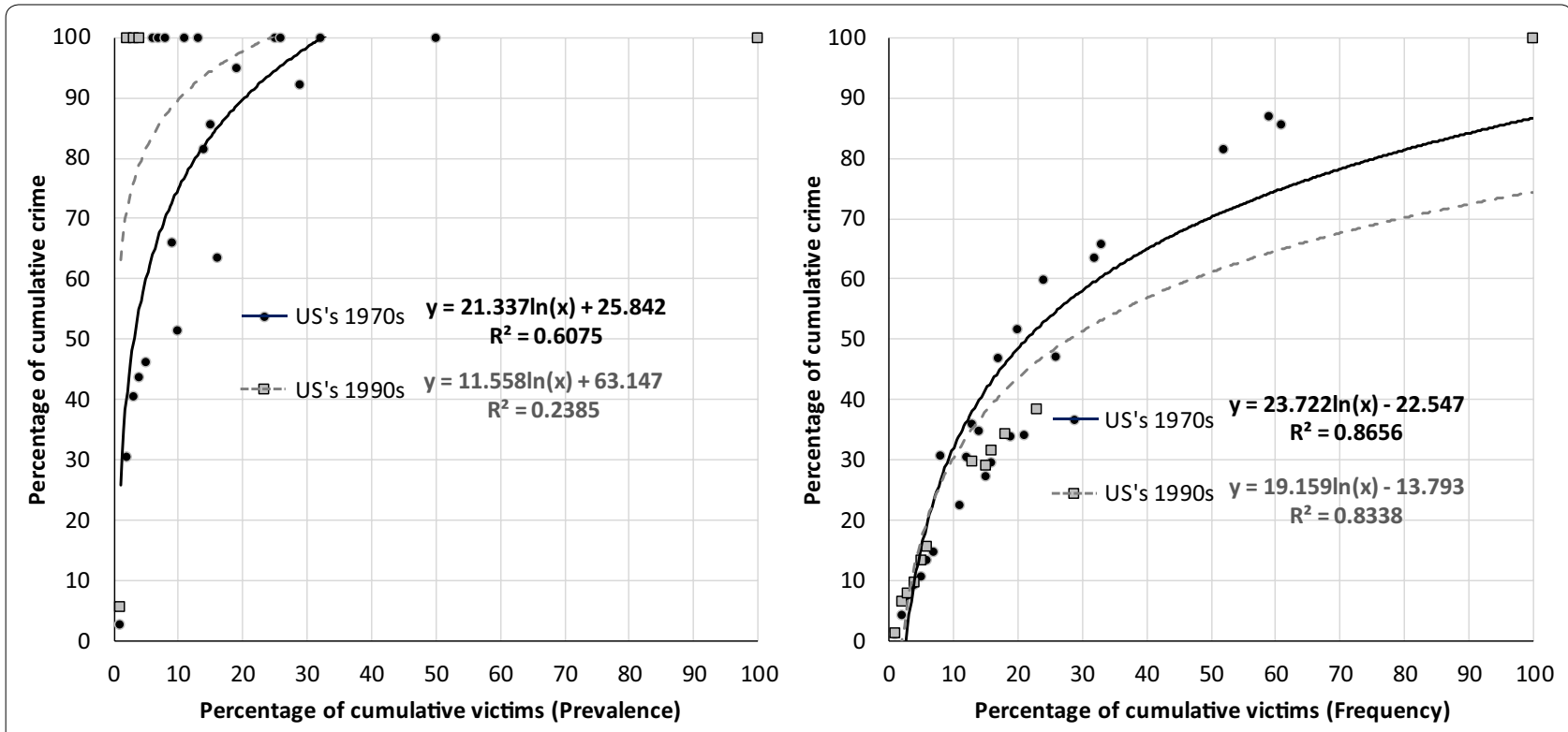

Fig. 5 Concentrations of crime among victims across different decades in the US

use the relevant data for each country or time period (e.g., if a study displayed results for both the UK and the US, the UK data was included in the UK analysis and the US data was included in the US analysis).

Figure 6 shows the distributions for prevalence and frequency for four decades. In the left panel, we see that three decades (1980s, 1990s and the 2000s) have quite similar quite similar distributions, but seem to be different than the decade of the 1970s (see Appendix 2). In fact, the most victimized 5\% in the UK during the 1980s, 1990 s and 2000s have approximately $59-65 \%$ of crime, whereas most victimized $5 \%$ during the 1970 s have only about $38.6 \%$ of crime (see Appendix 2). About $40 \%$ of the population has zero crime during 1970s whereas 50-60\% of the population has zero crime during other decades.

According to the frequency curves, the 2000s show the least concentration compared to the other three decades when we only consider targets with at least one victimization. In fact, the most victimized $5 \%$ of victims in the 1980 s and 1990 s experienced 27.4 and $31 \%$ of victimization respectively, whereas most victimized $5 \%$ of repeat victims during the 2000 s experienced only about $20.3 \%$ of crime (see Appendix 2). Overall, the UK frequency curves show that victimization concentration increased gradually from 1970 s to 1990 s, then dropped substantially into the 2000s (see Appendix 2).

\section{Limitations}

The heterogeneity of the literature on victimization and the sheer scarcity of studies found for particular categories of victimization create limitations to our findings. We alluded to most of these limitations in the previous sections, but they warrant reiteration here.

First, the 70 studies we found included various types of victimizations, including sexual victimization (Fisher et al. 1998; Gagné et al. 2005; Gidycz et al. 1993; Tillyer et al. 2016) and peer victimization (Bond et al. 2001; Espelage et al. 2013; Fekkes et al. 2004; Fisher et al. 2015; Pabian and Vandebosch 2016; Li et al. 2003). However, many of those studies did not satisfy our third criteria requiring at least two empirical ordered pairs, and so we excluded them. Thus, we ended up with few types of victimization for our meta-analysis.

Second, visual binning can reduce the true variation in the $\mathrm{X}$ and $\mathrm{Y}$ points. Losing variations in the raw data reduces the degrees of freedom, and can lead to a less accurate estimation of the curve. For example, we found that some of the estimated betas (in Figs. 3 and 5) were not statistically significant (see italicized estimates in Appendix 2). Theoretically, this finding does not make sense because it suggests that there is no significant evidence of victim concentration. Despite this limitation, we used bin medians rather than means because there is no 

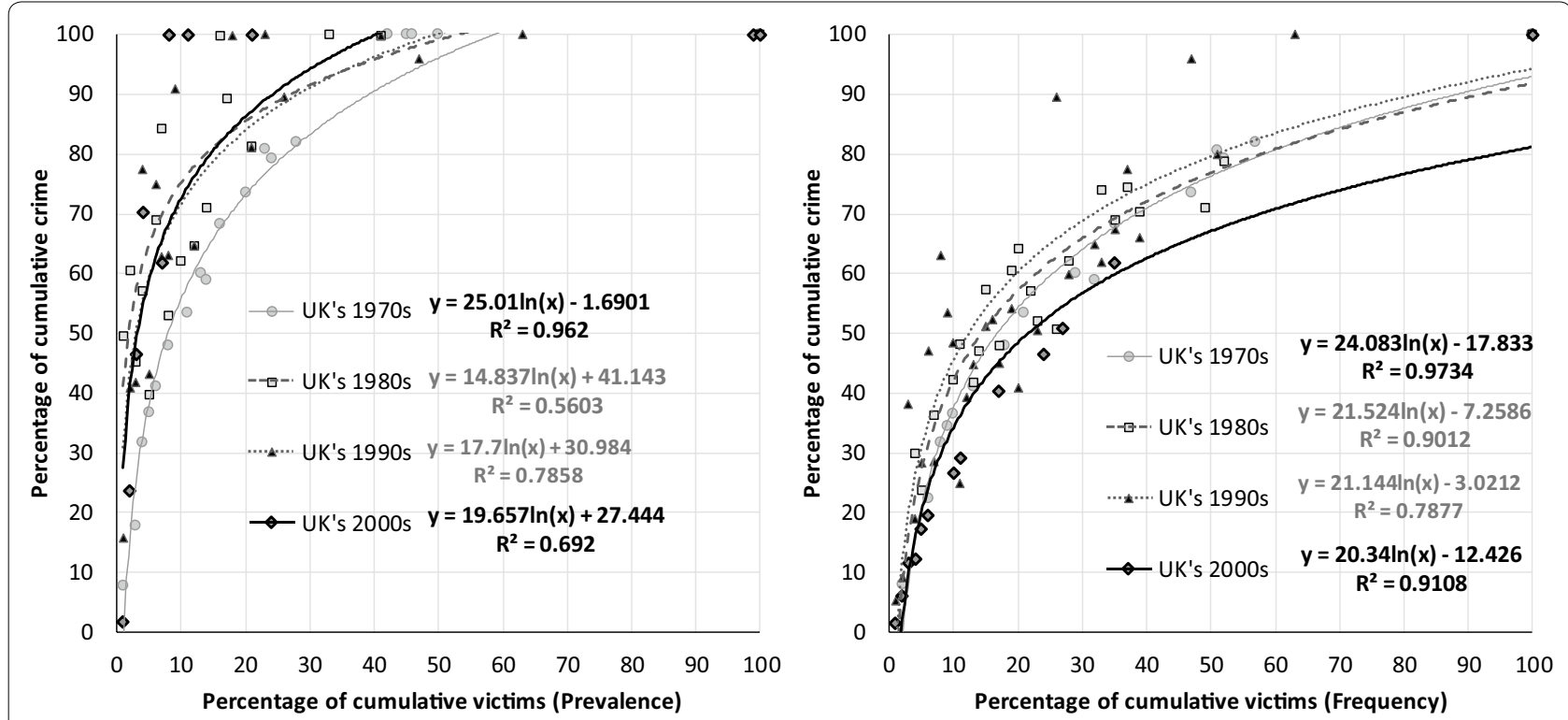

Fig. 6 Concentrations of crime among victims across different decades in the UK

other metric to represent the typicality of each bin, given the skewness of the distributions within bins.

Third, we did not weight our data nor $X-Y$ pairs. Because data from a large sample can be more reliable and have more statistical power for a meta-analysis than data from a small sample, weighting by sample size would be reasonable. However, because we did not find any substantial difference in the findings by using the weighting method, we used the unweighted data points for metaanalysis. Based on our analysis, we believe weighting makes no difference, but there is always the possibility that we could be wrong.

Fourth, we used the logarithmic function throughout the meta-analyses. Because the logarithmic transformation is not possible for zero, all curves in the figures are marginally away from the origin either vertically or horizontally. Using functional forms tailored to suit different categories of victimization concentration may be better than a using a standard logarithmic function. The extreme upper right in our estimated curves are likely to be biased in most of the figures. The most important part of the curves is toward the lower left were the most victimized subjects appear. The logarithmic functions fit the data well here, as judged by the dispersion of cases around the fitted lines. In future research, other functional forms should be tested.
Finally, our findings are limited by the populations researchers have examined with sufficient frequency that we could make comparisons. We could only compare concentration levels of the UK to the US, for example, because sufficient number of $\mathrm{X}-\mathrm{Y}$ pairs are given for reliable comparison. Other national comparisons would be interesting, but there are insufficient studies to make such comparisons.

\section{Discussion and conclusions}

This is the first study to systematically review studies on the concentration of victimization and to synthesize their findings using a form of meta-analysis. One of the reasons researchers use systematic reviews and meta-analysis is to avoid potentially biased conclusions that can arise from standard narrative reviews (Wilson 2001). Prior to conducting a meta-analysis, it is quite possible that the community of scholars examining a topic is wrong in their conclusions. Now that we have conducted a metaanalysis of repeat victimization studies, our findings suggest that the scholars who promote the importance of repeat victimization are correct. Though this may seem obvious, the obviousness of our findings is not the point: in principle, the findings could have been otherwise.

The studies collectively show that a relatively few households and businesses have a disproportionate 
number of victimizations. When all possible victims are included (regardless of whether they have experienced victimization during a study's reference period), $5 \%$ of the subjects have $60 \%$ of the victimizations. When only those who have experience at least one victimization are examined, the $5 \%$ most victimized subjects have $12 \%$ of the victimizations. On average, therefore, the biggest source of victimization concentration is due to the non-involvement in crime of most subjects. It seems plausible that much of the cause of the first source of concentration is due to population heterogeneity-some people, households, or businesses are at less risk of crime than others due to some characteristics they do not share with others who are at greater risk. In fact, our findings suggest that about $50 \%$ of population of businesses and $20 \%$ of population of households have experienced victimization and this can be attributed to the difference in the features of places in terms of crime opportunities. However, additional concentration is due to repeated victimization of a minority of victims after the first victimization. And state dependence is more likely to be an explanation for repeated victimization following the first victimization.

Furthermore, we found that high involvement in crime is associated with high repetition once involved. Though this is a rough summary of our findings, it is tantalizing and deserving of further enquiry. The reasoning for this is twofold, implying (1) that involvement and repetition are not separate processes that require different explanations and (2) that mixed processes of flag and boost account (i.e., population heterogeneity and state dependence, respectively) operate at the aggregate level. Fortunately, we are not the only researchers to point out this association. Trickett et al. (1992, 1995) found that high crime rates can be attributed to both measures of victimization, high crime prevalence and high crime repetition. These findings suggest that crime prevention should focus on preventing initial victimization and on preventing subsequent (repeat) victimizations as well. Economic efficiency, however, suggests focusing more on the previously victimized, as this is a much smaller portion of the population so it is easier to concentrate prevention programs. Accordingly, having two different measures of victimization concentration is necessary. Though this conclusion reiterates what others have said about victimization, no study has systematically analyzed and confirmed this conclusion. When we began, it was possible that our review could contradict what researchers thought they would know, or it could confirm it. The fact that in this case the community was probably right, is a useful finding. From this standpoint, reasserting the need for two different measures for victimization concentration is useful.

Based on the victimization comparisons between frequency and prevalence, households and businesses, property and personal, the UK and the USA, and across the decades (i.e. over time) in each of these countries, we conclude our paper as follows.

First, the variation between households and businesses among the targets with at least one victimization, suggests that on average, households do better at avoiding subsequent crimes than managers of businesses: a smaller proportion of households are at the upper end of repeat involvement than is the case with businesses. For businesses that experience repeat victimization, changing management practices through the adoption of more protective measures may be costly and inconvenient. Especially when they do not make much profit in more crime ridden places, they might prefer to put up with repeat victimization. In contrast, households may put forth more effort to reduce criminal opportunities because repeat victimizations are more expensive and inconvenient. This finding emphasizes the role of place management in reducing repeat victimization at places (Madensen and Eck 2013). Thus, increasing the responsibility of place managers or owners through the application of publicity, user fees, or even civil actions might reduce a substantial amount of business victimization (Weisel 2005). However, it is still possible that the difference between households and businesses can be attributed to the different data collection process from different surveys.

Second, the comparison between personal and property victimizations suggests that the patterns of revictimization are similar once a target has been victimized. If we assume that personal crime is a crime against person and that property crime is a crime at a place, this is consistent with the findings in Eck et al. (2017, in this issue). In other words, victim concentration is not substantially different from place concentration in the frequency curves.

Third, in the variation between decades in the US, the findings suggest that during 1990s, the percentage of the population that was victimized decreased and the targets with at least one victimization generally experienced less repeat victimization. Thus, findings are consistent with victimization trend across decades with the sharp decline in all categories of crime and all parts of the nation during 1990s (Zimring 2006). 
This first meta-analysis of repeat victimization raises a number of questions about the variation in crime concentration among people, households, and businesses. It does, however, show that, when data is available to draw a conclusion, concentration of crime among people, households and businesses is standard. We found no study that contradicted this finding. Nor did we find any study that suggests that the concentration is due only to prevalence (the proportion of subjects who were victimized one or more times) or only due to frequency (the repetition of victimization given an initial victimization). Though it should not need repeating, given crime policy makers proclivity to fads, we do repeat that the concentration of crime among a relatively small proportion of possible crime targets must be part of any sensible prevention policy.

\section{Authors' contributions}

This paper was conducted by a team. SO was the lead writer for this paper, contributed to the development of the methods used, and provided expertise on victims. NNM provided expertise on offenders, assisted in the development of the research methods, and provided editorial reviews. YJL was the lead analyst for the team and provided editorial assistance. JEE headed the team and provided overall guidance and editorial assistance. All authors read and approved the final manuscript.

\section{Author details}

${ }^{1}$ School of Criminal Justice, University of Cincinnati, Cincinnati, OH, USA.

${ }^{2}$ School of Public Affairs, University of Colorado, Colorado Springs, USA.

\section{Competing interests}

The authors declare that they have no competing interests.

\section{Availability of data and materials}

Articles used in the systematic review are noted in the references. For other information regarding data, please contact the lead author.

\section{Ethics approval and consent to participate}

Does not apply. As a review of summary data from previously conducted research, no humans (or their tissues) participated as subjects in this research.

\section{Funding}

No funds were solicited or provided for this research.

\section{Publisher's Note}

Springer Nature remains neutral with regard to jurisdictional claims in published maps and institutional affiliations.

\section{Appendix 1}

Estimated distributions of crime at victim for prevalence and frequency schema: A comparison of fitted lines between un-weighted and weighted $\mathrm{X}-\mathrm{Y}$ ordered pairs (Figs. 7, 8)

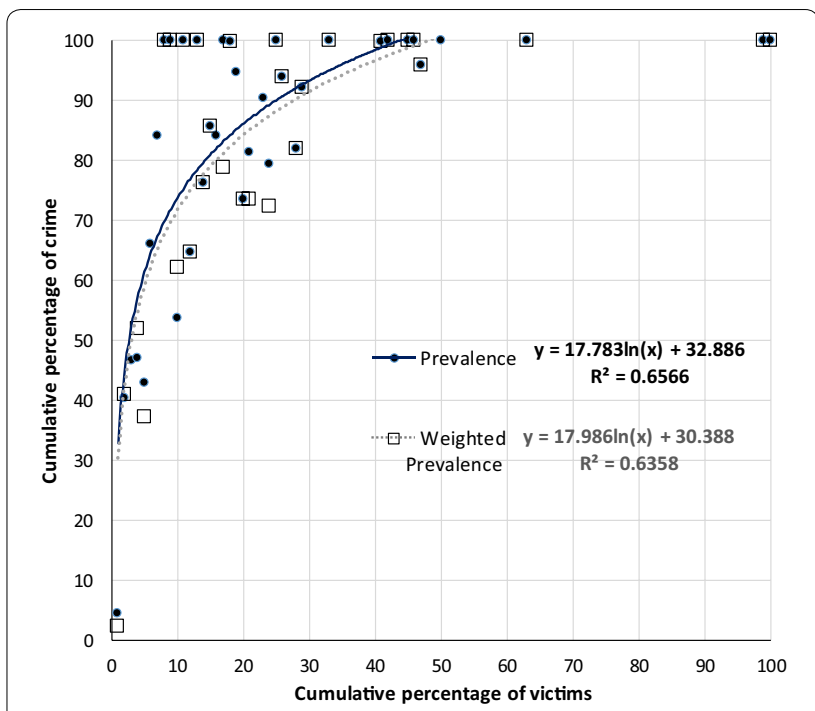

Fig. 7 Concentration including non-involved

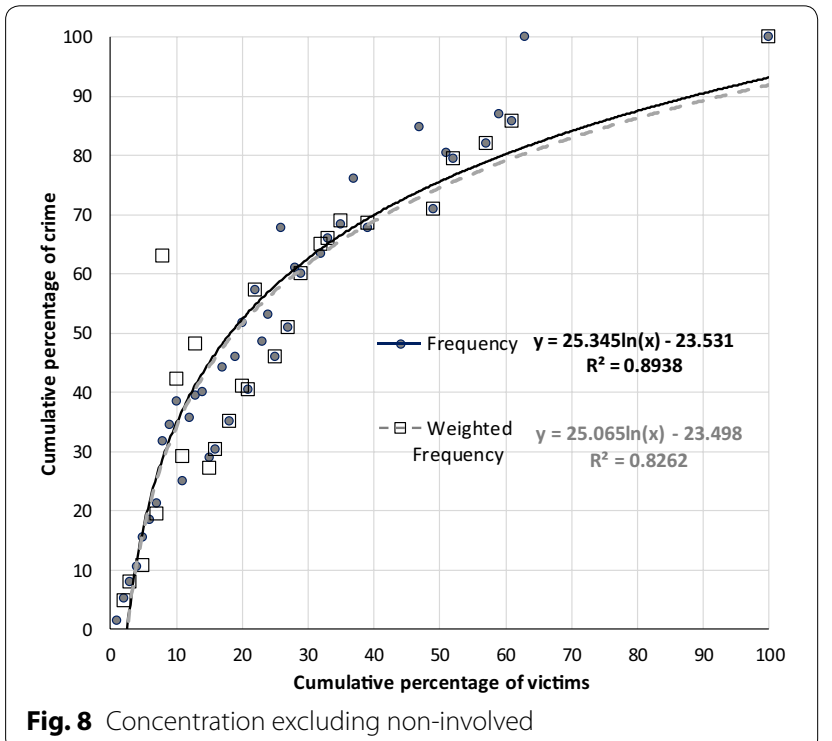

Fig. 8 Concentration excluding non-involved 


\section{Appendix 2}

See Table 2

Table 2 Estimated coefficients and summary statistics of the models specifications in Figs. 1, 2, 3, 4 and 5

\begin{tabular}{|c|c|c|c|c|c|c|c|c|c|c|c|}
\hline \multirow[t]{2}{*}{ Figure number } & \multirow[t]{2}{*}{ Key } & \multirow[t]{2}{*}{ Constant } & \multirow[t]{2}{*}{ Beta } & \multirow[t]{2}{*}{ Std. error } & \multicolumn{2}{|c|}{$\begin{array}{l}\text { Confidence } \\
\text { interval }\end{array}$} & \multirow[t]{2}{*}{ t-statistic } & \multicolumn{4}{|c|}{$\begin{array}{l}\text { Percentage of crime explained } \\
\text { by: }\end{array}$} \\
\hline & & & & & & & & $5 \%$ & $10 \%$ & $20 \%$ & $50 \%$ \\
\hline \multirow[t]{2}{*}{ Figure 1} & Prevalence & 32.89 & 17.78 & 2.11 & 13.56 & 22.01 & 8.41 & 61.5 & 73.8 & 86.2 & 100.0 \\
\hline & Frequency & -23.53 & 25.35 & 1.35 & 22.65 & 28.04 & 18.81 & 17.3 & 34.8 & 52.4 & 75.6 \\
\hline \multirow[t]{4}{*}{ Figure 2} & Household (P) & 23.69 & 24.61 & 3.68 & 17.25 & 31.97 & 6.69 & 63.3 & 80.4 & 97.4 & 100.0 \\
\hline & Business (P) & 28.95 & 18.01 & 2.58 & 12.85 & 23.16 & 6.98 & 57.9 & 70.4 & 82.9 & 99.4 \\
\hline & Household (F) & -15.28 & 21.017 & 1.66 & 17.70 & 24.33 & 12.68 & 18.5 & 33.1 & 47.7 & 66.9 \\
\hline & Business (F) & -4.86 & 22.121 & 3.72 & 14.69 & 29.56 & 5.95 & 30.7 & 46.1 & 61.4 & 81.7 \\
\hline \multirow[t]{4}{*}{ Figure 3} & Property (P) & 26.10 & 23.087 & 4.10 & 14.89 & 31.28 & 5.64 & 63.3 & 79.3 & 95.3 & 100.0 \\
\hline & Personal (P) & 60.98 & $\underline{12.0206}$ & 5.76 & 0.50 & 23.54 & $\underline{2.12}$ & 80.3 & 88.7 & 97.0 & 100.0 \\
\hline & Property (F) & -14.65 & 20.476 & 1.91 & 16.66 & 24.29 & 10.73 & 18.3 & 32.5 & 46.7 & 65.5 \\
\hline & Personal (F) & -14.56 & 22.045 & 2.69 & 16.67 & 27.42 & 8.22 & 20.9 & 36.2 & 51.5 & 71.7 \\
\hline \multirow[t]{4}{*}{ Figure 4} & US (P) & 37.12 & 17.847 & 4.32 & 9.20 & 26.49 & 4.13 & 65.8 & 78.2 & 90.6 & 100.0 \\
\hline & Non-US (P) & 23.97 & 19.503 & 1.77 & 15.96 & 23.05 & 11.00 & 55.4 & 68.9 & 82.4 & 100.0 \\
\hline & US (F) & -22.31 & 23.273 & 1.93 & 19.41 & 27.14 & 12.03 & 15.1 & 31.3 & 47.4 & 68.7 \\
\hline & Non-US (F) & -16.82 & 23.962 & 1.34 & 21.29 & 26.64 & 17.92 & 21.7 & 38.4 & 55.0 & 76.9 \\
\hline \multirow[t]{4}{*}{ Figure 5} & US 1970'(P) & 25.84 & 21.337 & 3.84 & 13.67 & 29.01 & 5.56 & 60.2 & 75.0 & 89.8 & 100.0 \\
\hline & US 1990'(P) & 63.15 & $\underline{11.558}$ & 11.93 & -12.29 & 35.41 & $\underline{0.97}$ & 81.7 & 89.8 & 97.8 & 100.0 \\
\hline & US 1970'(F) & -22.55 & 23.722 & 1.91 & 19.91 & 27.54 & 12.43 & 15.6 & 32.1 & 48.5 & 70.3 \\
\hline & US 1990'(F) & -13.79 & 19.159 & 2.71 & 13.75 & 24.57 & 7.08 & 17.0 & 30.3 & 43.6 & 61.2 \\
\hline \multirow[t]{8}{*}{ Figure 6} & UK 1970'(P) & -1.69 & 25.01 & 1.21 & 22.60 & 27.42 & 20.74 & 38.6 & 55.9 & 73.2 & 96.1 \\
\hline & UK 1980' (P) & 41.14 & 14.837 & 3.19 & 8.46 & 21.21 & 4.65 & 65.0 & 75.3 & 85.6 & 99.2 \\
\hline & UK 1990' (P) & 30.98 & 17.7 & 2.24 & 13.22 & 22.18 & 7.90 & 59.5 & 71.7 & 84.0 & 100.0 \\
\hline & UK $2000^{\prime}(P)$ & 27.44 & 19.657 & 4.64 & 10.38 & 28.93 & 4.24 & 59.1 & 72.7 & 86.3 & 100.0 \\
\hline & UK 1970'(F) & -17.83 & 24.083 & 1.06 & 21.96 & 26.21 & 22.63 & 20.9 & 37.6 & 54.3 & 76.4 \\
\hline & UK 1980'(F) & -7.26 & 21.524 & 1.59 & 18.34 & 24.71 & 13.51 & 27.4 & 42.3 & 57.2 & 76.9 \\
\hline & UK 1990'(F) & -3.02 & 21.144 & 2.04 & 17.07 & 25.22 & 10.37 & 31.0 & 45.7 & 60.3 & 79.7 \\
\hline & UK 2000' (F) & -12.43 & 20.34 & 1.92 & 16.50 & 24.18 & 10.60 & 20.3 & 34.4 & 48.5 & 67.1 \\
\hline
\end{tabular}

Received: 17 February 2017 Accepted: 6 July 2017

Published online: 26 July 2017

\section{References}

${ }^{\dagger}$ Denotes a study we identified through keyword search; *Denotes a study included in both the systematic review and meta-analysis ${ }^{\dagger}$ Averdijk, M. (2011). Reciprocal effects of victimization and routine activities. Journal of Quantitative Criminology, 27(2), 125-149.

${ }^{\dagger}$ Akers, R. L., Sellers, C., \& Cochran, J. (1987). Fear of crime and victimization among the elderly in different types of communities. Criminology, 25(3), 487-505.

Ashton, J., Brown, I., Senior, B., \& Pease, K. (1998). Repeat victimisation: offender accounts. International Journal of Risk Security and Crime Prevention, 3, 269-280.

Bennett, T. (1995). Identifying, explaining, and targeting burglary 'hot spots'. European Journal on Criminal Policy and Research, 3(3), 113-123.

${ }^{\dagger}$ Bennett, D. C., Guran, E. L., Ramos, M. C., \& Margolin, G. (2011). College students' electronic victimization in friendships and dating relationships:
Anticipated distress and associations with risky behaviors. Violence and Victims, 26(4), 410-429.

Blumstein, A., \& Wallman, J. (2006). The crime drop in America. Cambridge: Cambridge University Press.

†Bond, L., Carlin, J. B., Thomas, L., Rubin, K., \& Patton, G. (2001). Does bullying cause emotional problems? A prospective study of young teenagers. British Medical Journal, 323(7311), 480.

${ }^{\dagger}$ Brzozowski, J. A., Taylor-Butts, A., \& Johnson, S. (2006). Victimization and offending among the aboriginal population in Canada. Juristat: Canadian Centre for Justice Statistics, 26(3), 1-31.

Chenery, S., Holt, J., \& Pease, K. (1997). Biting back ll: Reducing repeat victimisation in Huddersfield (Vol. 2). London: Home Office Police Research Group.

Eck, J. E., Lee, Y., SooHyun, O., \& Martinez, N. N. (2017). Compared to what? Estimating the relative concentration of crime at places using systematic and other reviews. Crime Science, 6, 6.

${ }^{*}$ Ellingworth, D., Farrell, G., \& Pease, K. (1995). Victim is a victim is a victim? Chronic victimization in four sweeps of the British Crime Survey. British Journal of Criminology, 35(3), 360-365.

†Espelage, D. L., Rao, M. A., \& De La Rue, L. (2013). Current research on schoolbased bullying: A social-ecological perspective. Journal of Social Distress and the Homeless, 22(1), 21-27. 
${ }^{\dagger}$ Fagan, A. A., \& Mazerolle, P. (2011). Repeat offending and repeat victimization: Assessing similarities and differences in psychosocial risk factors. Crime \& Delinquency, 57(5), 732-755

${ }^{\dagger}$ Farrell, G. (1992). Multiple victimisation: its extent and significance. International Review of Victimology, 2(2), 85-102.

${ }^{* \dagger}$ Farrell, G. (1995). Preventing repeat victimization. Crime and Justice, 19, 469-534.

${ }^{*}$ Farrell, G., \& Pease, K. (1993). Once bitten, twice bitten: Repeat victimisation and its implications for crime prevention. London: Home Office.

Farrell, G., Tilley, N., \& Tseloni, A. (2014). Why the crime drop? In M. H. Tonry (Ed.), Crime and justice: A review of research (Vol. 43, pp. 421-490). Chicago: University of Chicago Press.

${ }^{\dagger}$ Fekkes, M., Pijpers, F. I., \& Verloove-Vanhorick, S. P. (2004). Bullying behavior and associations with psychosomatic complaints and depression in victims. The Journal of Pediatrics, 144(1), 17-22.

Felson, M., \& Clarke, R. (1998). Opportunity makes the thief (Police Research Series Paper 98, Policing andreducing crime unit, research, development and statistics directorate). London: Home Office.

${ }^{\dagger}$ Fisher, B. S., Daigle, L. E., \& Cullen, F. T. (2010). What distinguishes single from recurrent sexual victims? The role of lifestyle-routine activities and firstincident characteristics. Justice Quarterly, 27(1), 102-129.

${ }^{\dagger}$ Fisher, B. S., Sloan, J. J., Cullen, F. T., \& Lu, C. (1998). Crime in the ivory tower: The level and sources of student victimization. Criminology, 36(3), 671-710.

${ }^{\dagger}$ Fisher, S., Middleton, K., Ricks, E., Malone, C., Briggs, C., \& Barnes, J. (2015). Not just black and white: peer victimization and the intersectionality of school diversity and race. Journal of Youth and Adolescence, 44(6), $1241-1250$.

${ }^{\dagger}$ Forero, R., McLellan, L., Rissel, C., \& Bauman, A. (1999). Bullying behaviour and psychosocial health among school students in New South Wales, Australia: cross sectional survey. British Medical Journal, 319(7206), 344.

Forrester, D., Chatterton, M., Pease, K., \& Brown, R. (1988). The Kirkholt burglary prevention project, Rochdale. London: Home Office.

Forrester, D., Frenz, S., O'Connell, M., \& Pease, K. (1990). The Kirkholt burglary prevention project: Phase ll. London: Home Office.

${ }^{\dagger}$ Gagné, M. H., Lavoie, F., \& Hébert, M. (2005). Victimization during childhood and revictimization in dating relationships in adolescent girls. Child Abuse \& Neglect, 29(10), 1155-1172.

Gill, M., \& Matthews, R. (1993). Raids on banks. Leicester: University of Leicester: Centre for the Study of Public Order.

Gill, M., \& Pease, K. (1998). Repeat robbers: Are they different? In Crime at work (pp. 143-153). London: Palgrave Macmillan UK.

${ }^{\dagger}$ Gidycz, C. A., Coble, C. N., Latham, L., \& Layman, M. J. (1993). Sexual assault experience in adulthood and prior victimization experiences. Psychology of Women Quarterly, 17(2), 151-168.

${ }^{\dagger}$ Gottfredson, M. R., \& Grande-Bretagne, (1984). Home office victims of crime: The dimensions of risk. London, UK: HM Stationery Office.

Higgins, J. P., \& Green, S. (2011). Cochrane handbook for systematic reviews of interventions: Version 5.1.0 (updated March 2011). The Cochrane collaboration. www.cochrane-handbook.org.

${ }^{*}$ Hindelang, M. J., Gottfredson, M. R., \& Garofalo, J. (1978). Victims of personal crime: An empirical foundation for a theory of personal victimization. Cambridge: Ballinger.

${ }^{\dagger}$ Holt, M. K., Finkelhor, D., \& Kantor, G. K. (2007). Multiple victimization experiences of urban elementary school students: Associations with psychosocial functioning and academic performance. Child Abuse \& Neglect, 31(5), 503-515.

Hope, T. (1995). The flux of victimization. British Journal of Criminology, 35(3), 327-342.

${ }^{\dagger}$ Hope, T., Bryan, J., Trickett, A., \& Osborn, D. R. (2001). The phenomena of multiple victimization. The relationship between personal and property crime risk. British Journal of Criminology, 41(4), 595-617.

${ }^{\dagger}$ Hough, M. (1986). Victims of violent crime: Findings from the British Crime Survey. In I. Anttila (Ed.), From crime policy to victim policy (pp. 117-132). London: Palgrave Macmillan UK.

${ }^{*}{ }^{\dagger} J o h n s o n$, S. D. (2008). Repeat burglary victimisation: a tale of two theories. Journal of Experimental Criminology, 4(3), 215-240.

†Johnson, S. D., Bowers, K., \& Hirschfield, A. (1997). New insights into the spatial and temporal distribution of repeat victimization. British Journal of Criminology, 37(2), 224-241.

†Jones, T., MacLean, B., \& Young, J. (1986). The Islington crime survey. Aldershot: Gower.
${ }^{\dagger}$ Kelly, L., Burton, S., \& Regan, L. (1996). Beyond victim or survivor: Sexual violence, identity and feminist theory and practice. In L. Adkins \& V. Merchant (Eds.), Sexualizing the social (pp. 77-101). London: Palgrave Macmillan UK.

${ }^{\dagger}$ Kilpatrick, D. G., Saunders, B. E., Veronen, L. J., Best, C. L., \& Von, J. M. (1987). Criminal victimization: Lifetime prevalence, reporting to police, and psychological impact. Crime \& Delinquency, 33(4), 479-489.

${ }^{\dagger}$ Kimerling, R., Alvarez, J., Pavao, J., Kaminski, A., \& Baumrind, N. (2007). Epidemiology and consequences of women's revictimization. Women's Health Issues, 17(2), 101-106.

${ }^{\dagger}$ Koss, M. P., Gidycz, C. A., \& Wisniewski, N. (1987). The scope of rape: incidence and prevalence of sexual aggression and victimization in a national sample of higher education students. Journal of Consulting and Clinical Psychology, 55(2), 162-170.

*† Lauritsen, J. L., \& Quinet, K. F. D. (1995). Repeat victimization among adolescents and young adults. Journal of Quantitative Criminology, 11(2), $143-166$.

${ }^{*}$ Laycock, G. (2001). Hypothesis-based research: The repeat victimization story. Criminology and Criminal Justice, 1(1), 59-82.

Lee, M. R. (2000). Community cohesion and violent predatory victimization: A theoretical extension and cross-national test of opportunity theory. Social Forces, 79(2), 683-706.

Lee, Y., Eck, J. E., SooHyun, O., \& Martinez, N. N. (2017). How concentrated is crime at places? A systematic review from 1970 to 2015. Crime Science. doi:10.1186/s40163-017-0069-x.

'Li, T., Trivedi, P. K., \& Guo, J. (2003). Modeling response bias in count: a structural approach with an application to the national crime victimization survey data. Sociological Methods \& Research, 31(4), 514-544.

*'Lloyd, S., Farrell, G., \& Pease, K. (1994). Preventing repeated domestic violence: A demonstration project on Merseyside. London: Home Office.

Madensen, T. D. \& Eck, J. E. (2013). Crime places and place management. In F. T. Cullen and P. Wilcox (Eds.), Oxford handbook of criminological theory, (pp. 554-578). New York

Martinez, N.N., Lee, Y., Eck, J.E., \& SooHyun, O. (2017). Ravenous wolves revisited: A systematic review of offending concentration. Crime Science (forthcoming)

* ${ }^{\dagger}$ Mayhew, P., Maung, N. A., \& Mirrlees-Black, C. (1993). The 1992 British crime survey. London: HM Stationery Office.

${ }^{\dagger}$ Menard, S. (2000). The "normality" of repeat victimization from adolescence through early adulthood. Justice Quarterly, 17(3), 543-574.

Mulrow, C. D., \& Oxman, A. (1997). How to conduct a Cochrane systematic review: Version 3.0.2. San Antonio: The Cochrane Collaboration.

${ }^{\dagger}$ Nansel, T. R., Overpeck, M., Pilla, R. S., Ruan, W. J., Simons-Morton, B., \& Scheidt, P. (2001). Bullying behaviors among US youth: Prevalence and association with psychosocial adjustment. JAMA, 285(16), 2094-2100.

${ }^{* \dagger}$ Nelson, J. F. (1980). Multiple victimization in American cities: a statistical analysis of rare events. American Journal of Sociology, 85(4), 870-891.

${ }^{*}$ Nelson, J. F. (1984). Modeling individual and aggregate victimization rates. Social Science Research, 13(4), 352-372.

Newman, M. E. (2005). Power laws, Pareto distributions and Zipf's law. Contemporary Physics, 46(5), 323-351.

Osborn, D. R., \& Tseloni, A. (1998). The distribution of household property crimes. Journal of Quantitative Criminology, 14(3), 307-330.

${ }^{\dagger}$ Osborn, D. R., Ellingworth, D., Hope, T., \& Trickett, A. (1996). Are repeatedly victimized households different? Journal of Quantitative Criminology, 12(2), 223-245.

${ }^{\dagger}$ Outlaw, M., Ruback, B., \& Britt, C. (2002). Repeat and multiple victimizations: the role of individual and contextual factors. Violence and Victims, 17(2), 187-204.

†Pabian, S., \& Vandebosch, H. (2016). An investigation of short-term longitudinal associations between social anxiety and victimization and perpetration of traditional bullying and cyberbullying. Journal of Youth and Adolescence, 45(2), 328-339.

${ }^{*}$ Pease, K. (1998). Repeat victimization: Taking stock. London: Home Office.

'Pease, K., \& Laycock, G. (1999). Revictimization, reducing the heat on hot victims (pp. 1-6). Canberra: Australian Institute of Criminology.

${ }^{*}$ Percy, S. L. (1980). Response time and citizen evaluation of police. Journal of Police Science and Administration, 8(1), 75-86.

${ }^{\dagger}$ Pereda, N., \& Gallardo-Pujol, D. (2014). One hit makes the difference: the role of polyvictimization in childhood in lifetime revictimization on a southern European sample. Violence and Victims, 29(2), 217-231. 
${ }^{\dagger}$ Planty, M., \& Strom, K. J. (2007). Understanding the role of repeat victims in the production of annual U.S. victimization rates. Journal of Quantitative Criminology, 23(3), 179-200.

${ }^{\dagger}$ Rand, M. R., \& Rennison, C. M. (2005). Bigger is not necessarily better: An analysis of violence against women estimates from the National Crime Victimization Survey and the National Violence Against Women Survey. Journal of Quantitative Criminology, 21(3), 267-291.

Rennison, C. M. (2001). Violent victimization and race, 1993-98. US Department of Justice, Office of Justice Programs, Bureau of Justice Statistics.

${ }^{\dagger}$ Rigby, K. E. N. (2000). Effects of peer victimization in schools and perceived social support on adolescent well-being. Journal of Adolescence, 23(1), 57-68.

${ }^{\dagger}$ Russell, D. E. (1984). Sexual exploitation. Beverly Hills: Sage.

'Sampson, A. (1991). Lessons from a victim support crime prevention project. London: Home Office.

Sampson, A., \& Phillips, C. (1992). Multiple victimisation: racial attacks on an East London estate. London: Home Office.

Sampson, A., \& Phillips, C. (1995). Reducing repeat racial victimisation on an East London estate. London: Home Office.

†Sandberg, D. A., Matorin, A. I., \& Lynn, S. J. (1999). Dissociation, posttraumatic symptomatology, and sexual revictimization: a prospective examination of mediator and moderator effects. Journal of Traumatic Stress, 12(1), 127-138.

Schwartz, D., Dodge, K. A., \& Coie, J. D. (1993). The emergence of chronic peer victimization in boys' play groups. Child Development, 64(6), 1755-1772.

${ }^{*}$ Sidebottom, A. (2012). Repeat burglary victimization in Malawi and the influence of housing type and area-level affluence. Security Journal, 25(3), $265-281$.

${ }^{\dagger}$ Siegal, J. M., Sorenson, S. B., Golding, J. M., Burnham, M. A., \& Stein, J. A. (1987). The prevalence of child sexual abuse: the Los Angeles epidemiological catchment area project. American Journal of Epidemiology, 126, 1141-1153.

†Sobsey, D. (1994). Sexual abuse of individuals with intellectual disability. In Craft, A. (Ed.). Practice issues in sexuality and learning disabilities (pp. 93-115). Routledge.

Sparks, R. F. (1981). Multiple victimization: Evidence, theory, and future research. The Journal of Criminal Law and Criminology (1973-), 72(2), 762-778.

${ }^{*}$ Sparks, R. F., Genn, H. G., \& Dodd, D. J. (1977). Surveying victims: A study of the measurement of criminal victimization, perceptions of crime, and attitudes to criminal justice. London: Wiley.

†Spelman, W. (1995). Once bitten, then what? cross-sectional and time-course explanations of repeat victimization. The British Journal of Criminology, 366-383.

${ }^{\dagger}$ Tilley, N. (1993). The prevention of crime against small businesses: The safer cities experience. London: Home Office.

†Tillyer, M. S., Gialopsos, B. M., \&Wilcox, P. (2016). The short-term repeat sexual victimization of adolescents in school. Crime \& Delinquency, 62(1), 81-106.
${ }^{\dagger}$ Toplu-Demirtas, E., Hatipoğlu-Sümer, Z., \& White, J. W. (2013). The relation between dating violence victimization and commitment among Turkish college women: does the investment model matter? International Journal of Conflict and Violence, 7(2), 203-215.

Trickett, A., Osborn, D. R., Seymour, J., \& Pease, K. (1992). What is different about high crime areas? British Journal of Criminology, 32(1), 81-89.

†Trickett, A., Ellingworth, D., Hope, T., \& Pease, K. (1995). Crime victimization in the eighties: Changes in area and regional inequality. British Journal of Criminology, 35(3), 343-359.

* Tseloni, A. (2000). Personal criminal victimization in the United States: fixed and random effects of individual and household characteristics. Journal of Quantitative Criminology, 16(4), 415-442.

${ }^{*}$ TSeloni, A. (2006). Multilevel modelling of the number of property crimes: household and area effects. Journal of the Royal Statistical Society: Series A, 169(2), 205-233.

${ }^{*}$ TTseloni, A., \& Pease, K. (2003). Repeat personal victimization. 'boosts' or 'flags'? British Journal of Criminology, 43(1), 196-212.

${ }^{\dagger}$ Tseloni, A., \& Pease, K. (2005). Population inequality: the case of repeat crime victimization. International Review of Victimology, 12(1), 75-90.

${ }^{*}$ Tseloni, A., \& Pease, K. (2015). Area and individual differences in personal crime victimization incidence: the role of individual, lifestyle/routine activities and contextual predictors. International review of victimology, 21(1), 3-29

${ }^{*}$ T'Tseloni, A., Wittebrood, K., Farrell, G., \& Pease, K. (2004). Burglary victimization in England and Wales, the United States and the Netherlands. British Journal of Criminology, 44(1), 66-91.

Webb, J. (1997). Direct line homesafe: an evaluation of the first year. Unpublished paper.

Weisel, D. L. (2005). Analyzing repeat victimization. Washington, DC: US Department of Justice, Office of Community Oriented Policing Services.

Wilson, D. B. (2001). Meta-analytic tools for criminology. Annals of the American Academy of Political and Social Science, 578, 71-89.

Winkel, F. W. (1991). Police, victims, and crime prevention: some researchbased recommendations on victim-orientated interventions. British Journal of Criminology, 31(3), 250-265.

${ }^{\dagger}$ Wittebrood, K., \& Nieuwbeerta, P. (2000). Criminal victimization during one's life course: The effects of previous victimization and patterns of routine activities. Journal of Research in Crime and Delinquency, 37(1), 91-122.

'Wolke, D., Woods, S., Stanford, K., \& Schulz, H. (2001). Bullying and victimization of primary school children in England and Germany: prevalence and school factors. British Journal of Psychology, 92(4), 673-696.

Wood, J., Wheelwright, G., \& Burrows, J. (1997). Crime against small business: facing the challenge: findings of a crime survey conducted in the Belgrave and West End areas of Leicester. Los Angeles: Crime Concern.

Zimring, F. E. (2006). The great American crime decline. USA: Oxford University Press.

\section{Submit your manuscript to a SpringerOpen ${ }^{\circ}$ journal and benefit from:}

- Convenient online submission

- Rigorous peer review

- Open access: articles freely available online

- High visibility within the field

- Retaining the copyright to your article

Submit your next manuscript at $\boldsymbol{\nabla}$ springeropen.com 